\title{
On the variations of ionospheric parameters made at a near equatorial station in the African longitude sector: IRI validation with the experimental observations
}

\author{
O. S. Oyekola ${ }^{1}$ and P. R. Fagundes ${ }^{2}$ \\ ${ }^{1}$ 307-143 Eighth Street, Etobicoke, Ontario, M8V 3C8, Canada \\ ${ }^{2}$ Universidade do Vale do Paraiba (UNIVAP), Sao Jose dos Campos, Sao Paulo, Brazil
}

(Received July 21, 2011; Revised October 10, 2011; Accepted October 15, 2011; Online published July 27, 2012)

\begin{abstract}
We examine the main morphological patterns and climatological behaviour of equatorial $F_{2}$ region over African sector using hourly observational values of $F_{2}$ peak height of maximum electron density $\left(h_{\mathrm{m}} F_{2}\right), F_{2}$ layer peak electron density $\left(N_{\mathrm{m}} F_{2} / f_{\mathrm{o}} F_{2}\right)$, and propagation factor $\left(M_{3000} F_{2}\right)$ hitherto made by the Ibadan ionosonde at $7.4^{\circ} \mathrm{N}$, $3.9^{\circ} \mathrm{E}$, dip latitude $2.3^{\circ} \mathrm{S}$, in Nigeria; between January to December 1958 , during a period of high solar activity (yearly averaged $R_{z 12}=190$ units) and magnetically quiet conditions $\left(K_{\mathrm{p}} \leq 3\right)$. A direct comparison between these measurements and the International Reference Ionosphere 2007 (IRI-2007) model-predictions are also made. The results of comparisons illustrate that good advancement has been made but reveal some important discrepancies. The trends in the experimental data are found to be in excellent agreement with the trends in the simulation results for maximum electron density and propagation factor, but fair-to-good for $F_{2}$ layer peak altitude. The model is unable to capture the sharp postsunset and predawn enhancements in $h_{\mathrm{m}} F_{2}$ and $M_{3000} F_{2}$, respectively. The model results have errors ranging from approximately $8-15 \%, 9-17 \%$, and 3-5\%, respectively, for $h_{\mathrm{m}} F_{2}, N_{\mathrm{m}} F_{2}$, and $M_{3000} F_{2}$. On average, the percent absolute relative difference of the model from the experimental observations varies from about $0-20 \%, 0-30 \%$, and $0-10 \%$ for $h_{\mathrm{m}} F_{2}, N_{\mathrm{m}} F_{2}$, and $M_{3000} F_{2}$, in that order. Our results are essentially consistent with other equatorial and low-latitude ground-based measurements over South America, India, and Southeast Asia.
\end{abstract}

Key words: Equatorial-ionosphere, ionosonde-data, IRI-2007, modeling and forecasting, ionospheric-parameter.

\section{Introduction}

The equatorial and low-latitude $F$ region ionosphere presents some perculiar characteristics behavior when compared to the middle and high latitude ionosphere. For example, in the daytime $E$ region (90-120 km), dynamo processes generate eastward electric fields, which are transmitted to $F$ region altitudes $(150-800 \mathrm{~km})$ by equipotential geomagnetic filed lines, causing both ions and electrons to drift upward, perpendicular to $\mathbf{B}$ with an $E \times B / B^{2}$ drift velocity (Anderson et al., 2002). At the same time, forces parallel to $\mathbf{B}$ due to gravity and plasma pressure gradients act to transport plasma along the magnetic field lines. The resultant effect is to create crests in electron density on either side of the magnetic equator at \pm 15 to 18 degrees dip latitudes known as the equatorial ionospheric anomaly (EIA) (e.g., Namba and Maeda, 1939; Appleton, 1946). Also just before the dusk the vertical plasma drift is enhanced and the EIA is intensified, followed by $F$ region lifting but the peak concentration decreases. The fast upward motion of the $F$ layer preceeds the occurrence of nighttime ionospheric plasma irregularities known as equatorial spread $F$ (ESF).

The International Reference Ionosphere (IRI) is a stan-

Copyright (C) The Society of Geomagnetism and Earth, Planetary and Space Sciences (SGEPSS); The Seismological Society of Japan; The Volcanological Society of Japan; The Geodetic Society of Japan; The Japanese Society for Planetary Sciences; TERRAPUB.

doi:10.5047/eps.2011.10.004 dard empirical model based on experimental observations of the ionospheric plasma (Bilitza, 2001). Its main purpose is to produce a relaible reference global model for the most important ionospheric parameters, such as electron density, ion composition, and electron and ion temperatures for undisturbed magnetic conditions. Furthermore, IRI are valuable for: (1) experimental design, (2) ionospheric radio propagation predictions, (3) testing theories on ionospheric phenomena, (4) the estimation of enviromental effects, (5) satellite orbit control, (6) tomography, and (7) checking various GPS data analysis and data reduction algorithms (Bradley, 1991; Bittencourt and Chryssafidis, 1994; Bilitza et al., 1995; Huang et al., 1996; Bilitza, 2001). Earlier studies of the analysis of the ionospheric key parameters and their comparison with previous model results of the International Reference Ionosphere (Bilitza, 2001) have been limited to only 1 month in a particular season to represent the behaviour for that season (e.g., Reinisch and Huang, 1996; Adeniyi et al., 2003; Abdu et al., 2004; Oyekola, 2011). However, some reports on the average behaviour of equatorial $F_{2}$ layer and their comparison with IRI model predictions are available (e.g., Lee and Reinisch, 2006; Bertoni et al., 2006; Rios et al., 2007; Sethi et al., 2008; Oyekola, 2010).

The primary aim of the investigation is to examine the detailed features of the temporal behavior of seasonally averaged ionospheric characteristic parameters of the $F_{2}$ re- 
gion at a near magnetic equatorial station located in Nigeria, West African region. Then we compare our experimental observations to the IRI-2007 model-predictions in an effort to validate the model results, to explore if there are any major differences, and to indicate specific period for these discrepancies.

The following section describes the data set and the method of analysis. In the results section, our general results are presented in Section 3, with diurnal structure and behavior of the key ionospheric parameters of equatorial $F$ region over Ibadan given in Subsection 3.1. A direct comparison between simulation results from IRI modelpredictions and experimental measurements from Ibadan for four different seasons is presented in Subsection 3.2. After that the percent relative deviations between IRI predictions and the ionospheric parameters under study are computed and discussed (Subsection 3.3). The next subsection addresses quantitative assessment of the model and the data (Subsection 3.4). Our results are discussed and summarized in Section 4.

\section{Data and Method}

The data used for this study were obtained from observations recorded by the ionospheric sounder located at Ibadan $\left(7.4^{\circ} \mathrm{N}, 3.9^{\circ} \mathrm{E}\right)$ between January and December 1958 during a period of very high solar activity and geomagnetically quiet periods. $F_{2}$ layer peak electron density, $N_{\mathrm{m}} F_{2}, \mathrm{~m}^{-3}$ was derived from the observed $F_{2}$ layer critical frequency, $f_{\mathrm{o}} F_{2}, \mathrm{MHz}: N_{\mathrm{m}} F_{2} \equiv 1.24 \times 10^{10} \times\left(f_{\mathrm{o}} F_{2}\right)^{2} . \quad M_{3000} F_{2}$ were directly scaled from ionograms. To obtain $F_{2}$ maximum heights, ionograms were manually reduced at each 1-h interval using ten-point Kelso (1952) technique. Geomagnetic quiet condition is defined as $K_{\mathrm{p}} \leq 3$. There were five international quiet days (IQD) in each month. For each month, five magnetically quiet days were selected for ionogram reduction and used to establish hourly mean values representative of the average vertical electron density profiles $N_{\mathrm{e}}(h)$ for each hour, for that month. Hourly and monthly values of the heights $h_{\mathrm{m}} F_{2}$ of the $F_{2}$ layer peak were then estimated from the vertical distribution of electron density. This is referred to as the ionosonde-observed $F_{2}$ peak height of electron density.

In order to study diurnal and seasonally averaged behaviour of the ionosphere over Ibadan, we grouped the 12month of the year into 4-month seasonal periods as follows: December solstice (November-December, JanuaryFebruary), June solstice (May-August), and equinoxes (March-April, September-October).

For comparison with the IRI-2007 model predictions, we used hourly monthly-median data of the above mentioned parameters. Here the months of March, June, September, and December were considered as representative of the March equinox, June solstice, September equinox, and December solstice, respectively. The IRI 2007 model values $h_{\mathrm{m}} F_{2}, N_{\mathrm{m}} F_{2}$, and $M_{3000} F_{2}$ used in our comparisons were downloaded from the IRI web site at: http://omniweb.gsfc.nasa.gov/vitmo/iri_vitmo.html. For the IRI options, CCIR model $h_{\mathrm{m}} F_{2}, f_{\mathrm{o}} F_{2}$, and $M_{3000} F_{2}$ were selected; for other IRI options, we use standard default specifications.
For the 12-month period of 1958 the monthly averaged smoothed sunspot numbers, $R_{z 12}$ were in the range of 181-201 with yearly averaged value of about 190 units. The monthly averaged values of $R_{z 12}$ for the months selected for comparisons were 201, 187, 184, and 181 for March, June, September, and December, respectively.

\section{Results}

3.1 Characteristics of ionospheric $F_{2}$-layer parameters at Ibadan

3.1.1 Height of the maximum electron concentration Figure 1 shows the variation of $h_{\mathrm{m}} F_{2}$ in December solstice (solid curve), June solstice (dashed curve), and equinoxes (short dotted curve) seasons. Figure 1 indicates typical duirnal and seasonally averaged characteristics behaviour of $h_{\mathrm{m}} F_{2}$ during high solar activity and quiet geomagnetic activity conditions. As can be seen, the patterns of variations are similar for all seasons. $F_{2}$ layer peak height is raised from an altitude of about $300 \mathrm{~km}$ at 0600 LT to: $\sim 650 \mathrm{~km}$ (December solstice), $\sim 580 \mathrm{~km}$ (June solstice), and $\sim 630 \mathrm{~km}$ (equinoxes) during the prereversal enhancement periods, $1800 \mathrm{LT}$ for December solstice and equinoxes, but 2000 LT for June solstice. Thereafter, $h_{\mathrm{m}} F_{2}$ descends gradually to a lower altitudes (slightly below $300 \mathrm{~km})$. Pre-sunrise minimum in $h_{\mathrm{m}} F_{2}$ is seen at 0400 LT for all seasons.

3.1.2 Maximum electron concentration Typical characteristics of quiet time diurnal and seasonal structures of $N_{\mathrm{m}} F_{2}$ at Ibadan are shown in Fig. 2. December solstice curve demonstrates noticeable prenoon and postnoon maxima. Here $N_{\mathrm{m}} F_{2}$ indicates a minimum value at about $0400 \mathrm{LT}$ for all season with a value of about $0.51 \times 10^{12} \mathrm{el} / \mathrm{m}^{3}, 0.27 \times 10^{12} \mathrm{el} / \mathrm{m}^{3}$ and $0.55 \times 10^{12} \mathrm{el} / \mathrm{m}^{3}$, respectively, for December solstice, June solstice, and

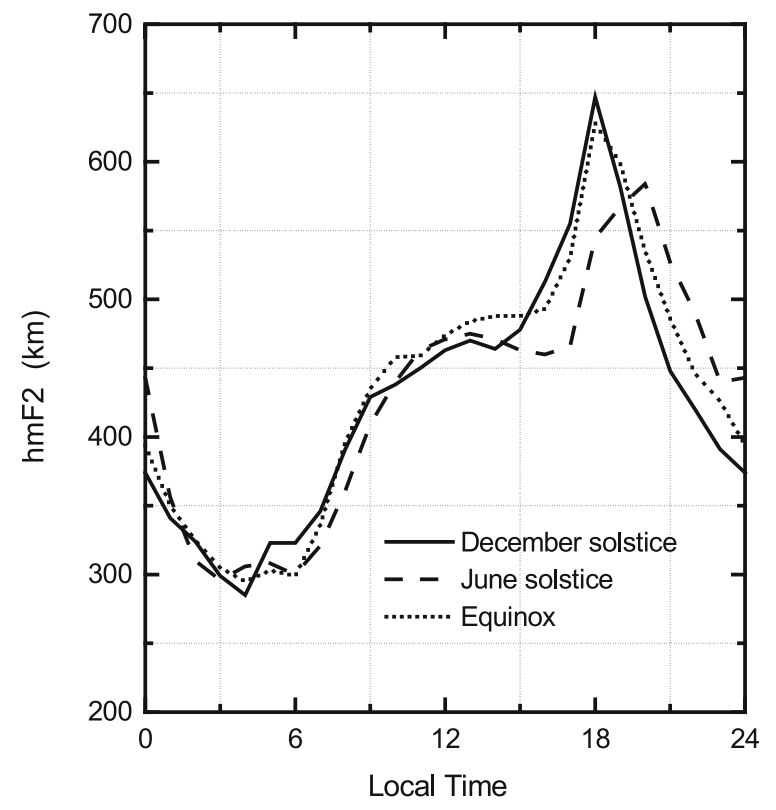

Fig. 1. Average $F_{2}$ layer peak altitude measured at Ibadan during December solstice (November-February), June solstice (May-August) and equinoxes (March-April, September-October) for quiet time and sunspot maximum conditions. 


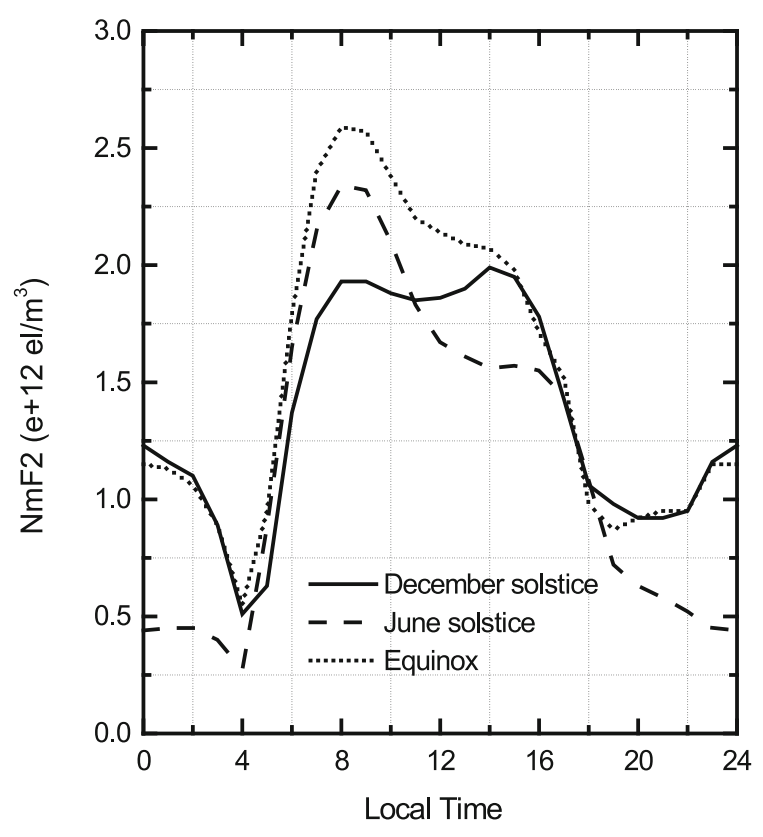

Fig. 2. Same as Fig. 1 except for $F_{2}$ layer maximum electron concentration.

equinoxes. Thereafter, there is a rapid increase until a prenoon maximum value of $\sim 1.93 \times 10^{12} \mathrm{el} / \mathrm{m}^{3}$, $2.34 \times 10^{12} \mathrm{el} / \mathrm{m}^{3}$, and $2.59 \times 10^{12} \mathrm{el} / \mathrm{m}^{3}$ is reached for December solstice, June solstice, and equinoxes, in that order. The slight decrease in peak electron density noted in December solstice is called the "noon bite-out". The postnoon peak is well formed in December solstice at 1400 LT, but relatively weaker for other two seasons. During December solstice the value of postnoon peak is marginally higher than the prenoon one.

Moreover, we note that higher values of $N_{\mathrm{m}} F_{2}$ are observed during the equinoxes between 0600 and 1500 LT (the so-called semiannual anomaly). $N_{\mathrm{m}} F_{2}$ values are higher in June solstice than December solstice from 0600-1000 LT, whereas opposite is the case for the nighttime period between 1800 and 0400 LT sector. This indicates the existence of the June solstice (winter) anomaly in $N_{\mathrm{m}} F_{2}$ over Ibadan during daytime in a period of high solar activity. One may also note that between local noon and 1600 LT, December solstice $N_{\mathrm{m}} F_{2}$ is greater in value than that of June solstice $N_{\mathrm{m}} F_{2}$.

3.1.3 Propagation factor Figure 3 compares the diurnal and seasonal changes of $M_{3000} F_{2}$ at Ibadan during high solar flux and magnetically quiet conditions. In general, $M_{3000} F_{2}$ increases steadily from 0000 LT and reach a peak at $0400 \mathrm{LT}$. After $0400 \mathrm{LT}, M_{3000} F_{2}$ then decreases gradually and get to minimum at around 1900 LT for all seasons. The trend appears to be fairly constant between 1000 and 1600 LT for the three seasons, but show discernible fluctuations from 1700-1800 LT, followed by a gradual increase until local midnight for all seasons. In general, seasonal variations seem to be less pronounced in $M_{3000} F_{2}$. One other point to note in Fig. 3 is that maximum value of $M_{3000} F_{2}$ occurs at the same local time when minimum values of both $h_{\mathrm{m}} F_{2}$ and $N_{\mathrm{m}} F_{2}$ occur (see observations 1 and 2). The reason for this is the strong anti-correlation that

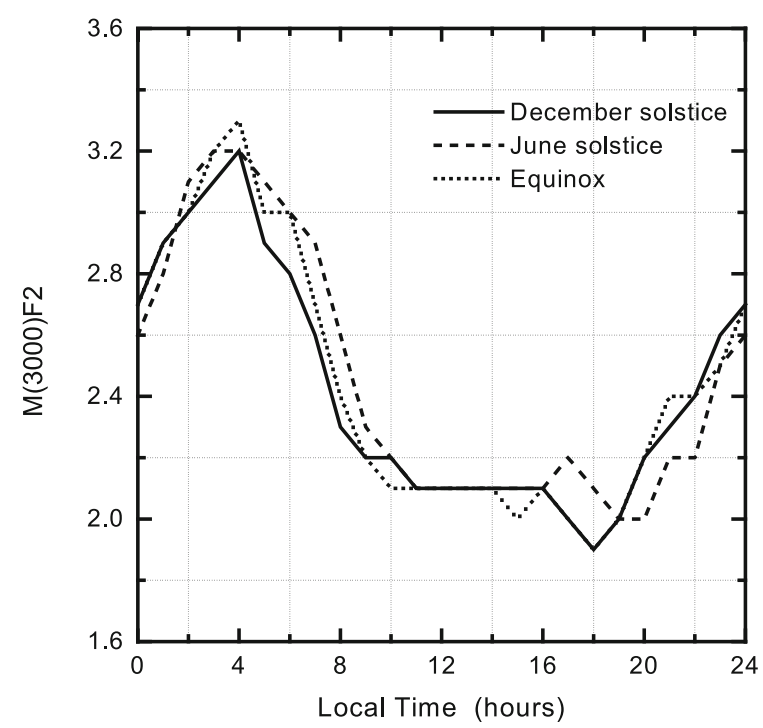

Fig. 3. Same as Fig. 1 except for propagation factor $M(3000) F_{2}$.

exist between $h_{\mathrm{m}} F_{2}$ and $f_{\mathrm{o}} F_{2}$ (hence $N_{\mathrm{m}} F_{2}$ ) and $M_{3000} F_{2}$ (Bilitza et al., 1979).

\subsection{Comparison between experimental results and the IRI model-predictions}

In Fig. 4 the diurnal variation of the observed and modeled $h_{\mathrm{m}} F_{2}$ values are presented for March (upper left panel), June (upper right panel), September (bottom left panel), and December (bottom right panel). As can be seen, between local midnight and 1000 local time the modeled height of the maximum electron concentrations closely followed their experimental behaviour. Large discrepancies are found in their morphological patterns from 1100 and 2300 local time. Notice that there are no data between 2200 and 0100 local time in the month of June. The most significant difference between the observations and model results is when the postsunset peak in the altitude of the $F_{2}$ peak occurs. The model captures predawn minimum, prenoon peak excellently well, but does not reproduce the sharp peak amplitude in $h_{\mathrm{m}} F_{2}$ that constantly seen in the observational data. This is as a result of low order spherical harmonics used in to develop CCIR model (D. Bilitza, private communication, 2011).

Figure 5 gives a direct comparison of the data and the model results of maximum electron concentrations for March (top left panel), June (top right panel), September (lower left panel), and December (lower right panel). Here it is quite obvious that the model results replicate the trends in the experimental data more closely, implying that CCIR $f_{\mathrm{o}} F_{2}$ option performs remarkable well. It is important to mention that the model reproduces $f_{\mathrm{o}} F_{2}$ sunrise depression and early morning enhancement, midday minimum, and postnoon peak for all the months. It is worth noticing that the model largely overestimates the nighttime electron densities values for June solstice season. As will be quantitatively shown later.

The plots in the upper left panel, upper right panel, lower left panel, and lower right panel in Fig. 6 shows comparisons for propagation factor between the ionosonde and IRI models for vernal equinox, June solstice, September 
Ibadan $\left(7.4^{\circ} \mathrm{N}, 3.9^{\circ} \mathrm{E}\right)$
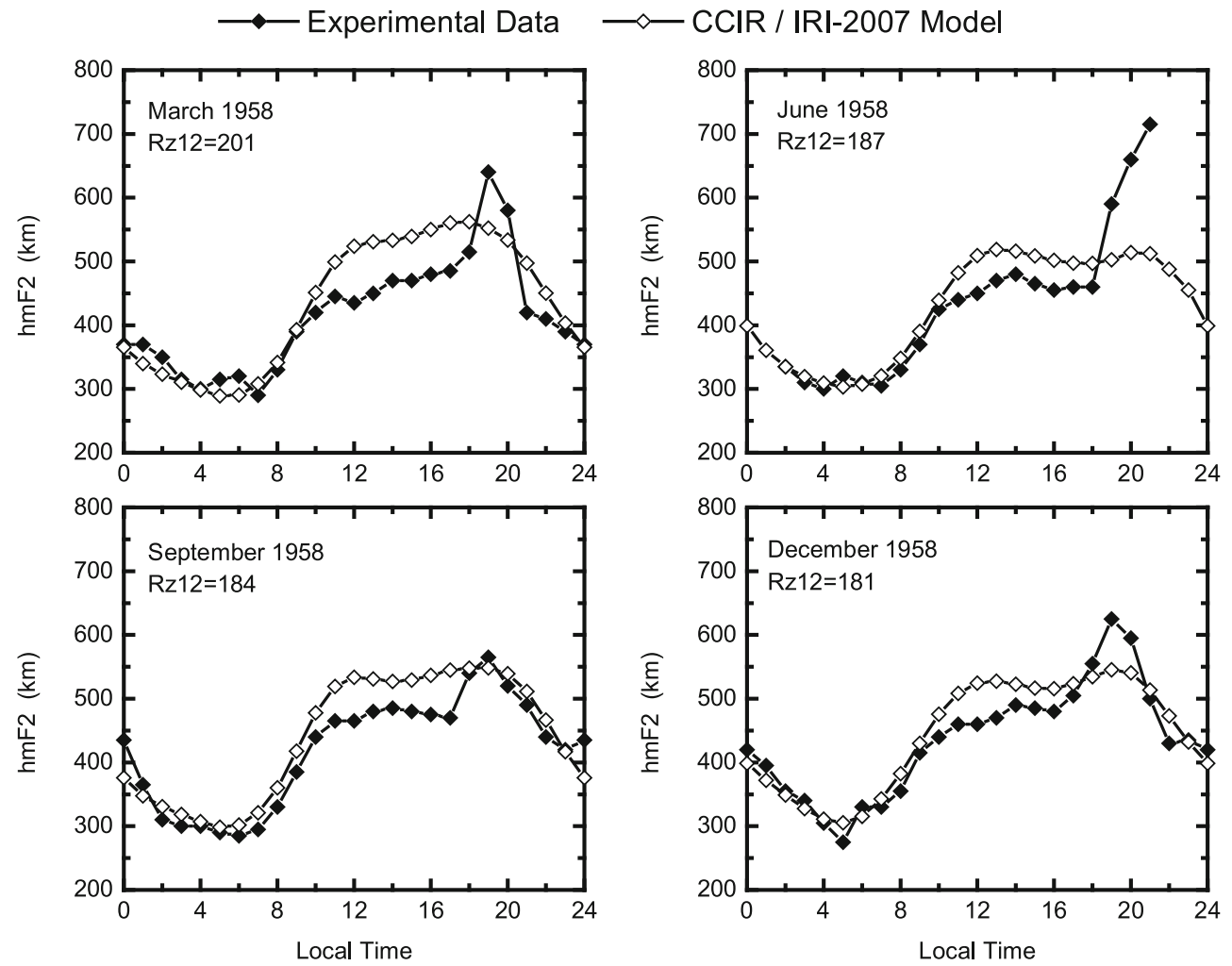

Fig. 4. Comparison between IRI model-predictions and experimental observations for the height of the ionospheric $F_{2}$-peak, $h_{\mathrm{m}} F_{2}$ at Ibadan for March (upper left plot), June (upper right plot), September (lower left plot), and December (lower right plot) during quiet time and sunspot maximum conditions. The 12-month average smoothed sunspot index, $R_{z 12}$ for each month is shown on the panel of each plot.

Ibadan $\left(7.4^{\circ} \mathrm{N}, 3.9^{\circ} \mathrm{E}\right)$
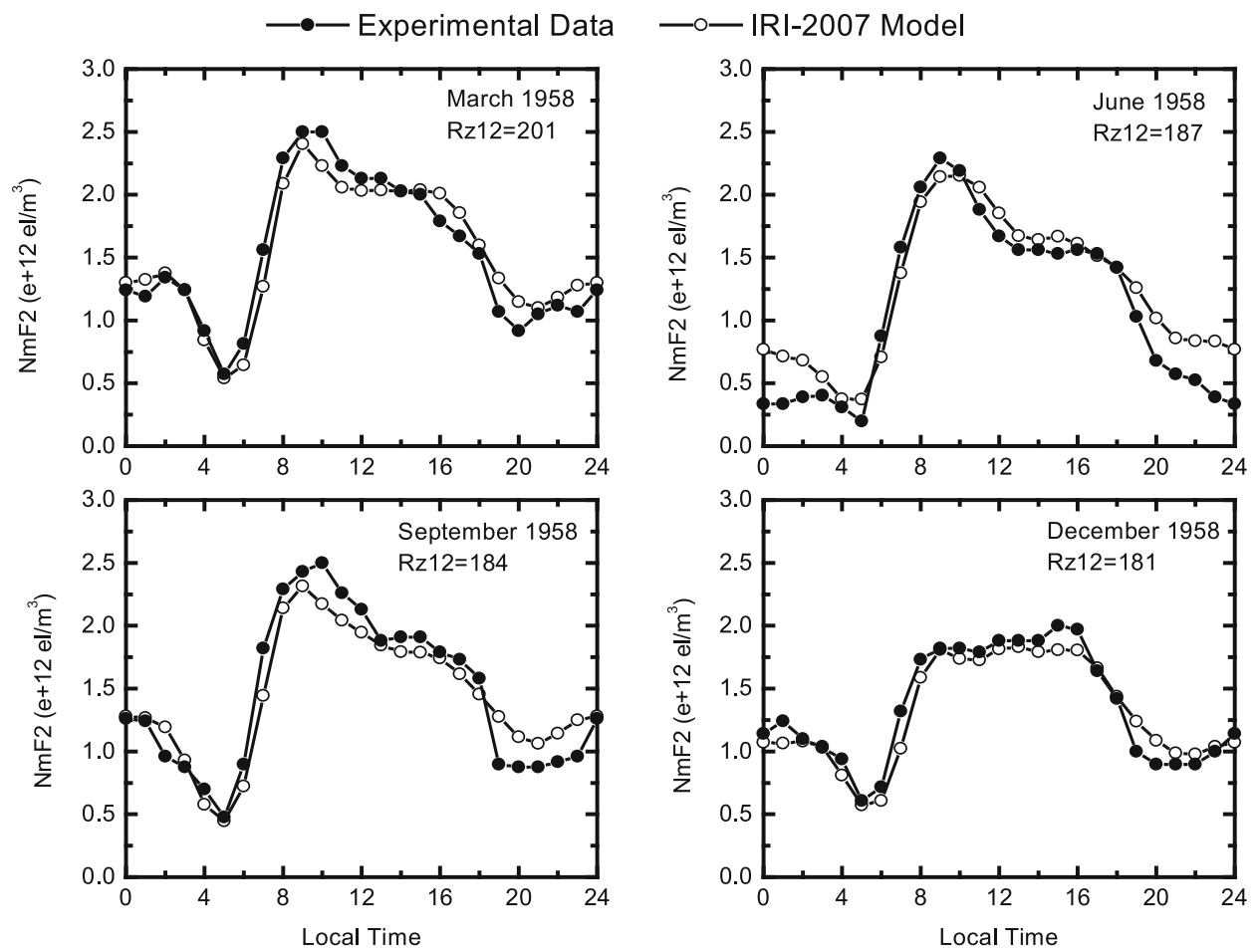

Fig. 5. Same as Fig. 4 except for $F_{2}$ layer maximum electron concentration. 

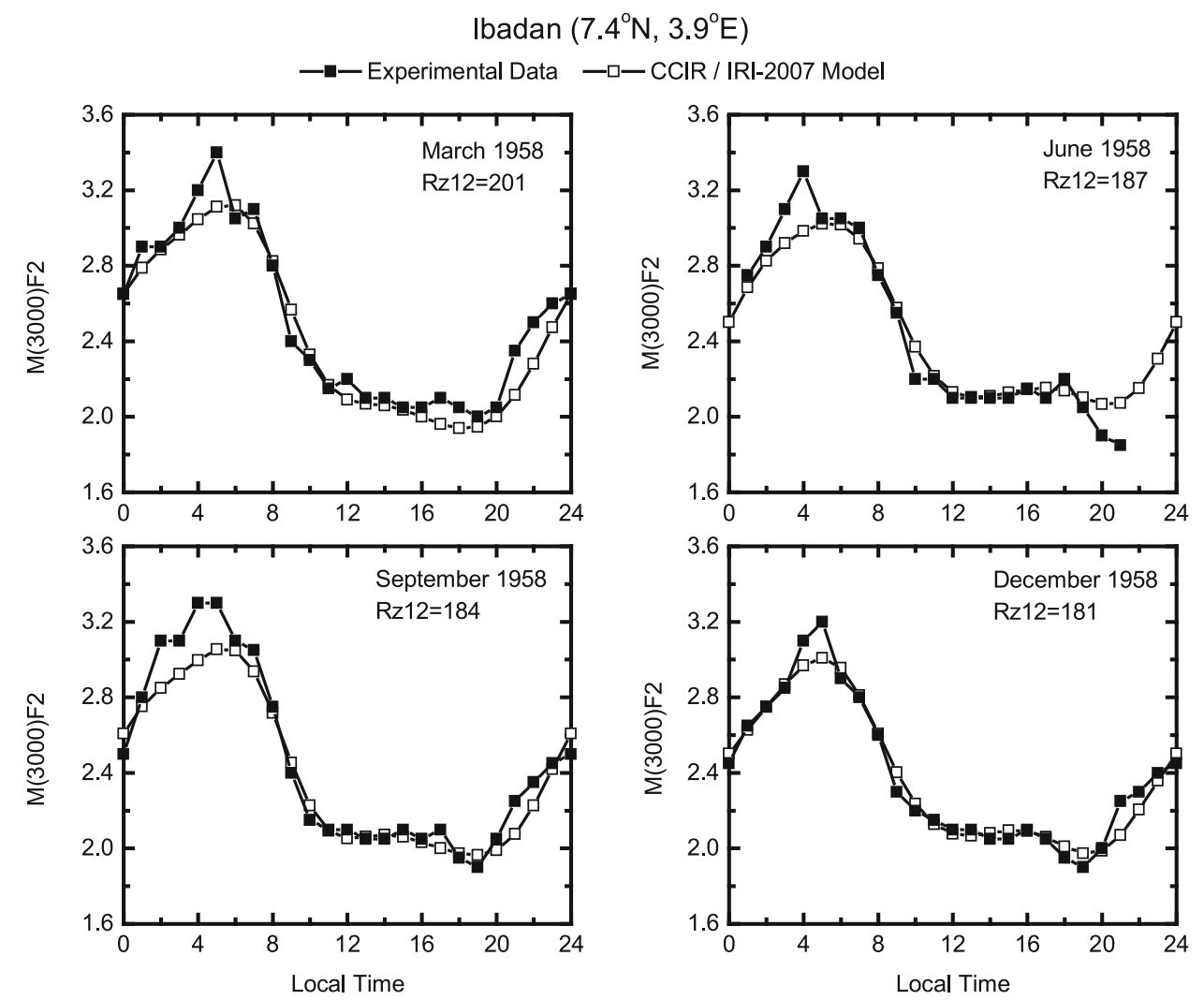

Fig. 6. Same as Fig. 4 except for propagation factor $M_{3000} F_{2}$.

equinox, and December solstice, respectively. There is no data between 2200 and local midnight, again during the month of June. Similar to the peak electron density results, the model generally provides excellent representation of their observational structure for all seasons. The most obvious disparity between the experimental and empirical curves is when the sharp peak in $M_{3000} F_{2}$ appears around dawn.

\subsection{Variation of percent relative deviations between model and data}

Beside IRI validation, we explore if there are any significant discrepancies between the measured and modeled results and to indicate specific time for these discrepancies. Consequently, the hourly relative deviations $\Delta X$ of each of the examined ionospheric parameters are calculated using the expression:

$$
\% \Delta X=\frac{X(\text { Modeled })-X(\text { Measured })}{X(\text { Measured })} * 100,
$$

where $X$ (Modeled) is the hourly monthly-median of modeled value of each parameter and $X$ (Measured) the corresponding hourly monthly-median value of the ionosonde data. According to Eq. (1) positive deviation denotes that the model overpredicts the data, while negative deviation implies that the IRI predictions underestimate the ionosonde data.

Figures 7-9 show the variation of the hourly relative deviations for the ionospheric parameters $h_{\mathrm{m}} F_{2}, N_{\mathrm{m}} F_{2}$, and $M_{3000} F_{2}$ after Eq. (1). These plots correspond to direct comparison between data and model shown in Figs. 4-6.

Figure 7 shows the percent relative deviations model re- sults from ionosonde data for March (top left panel), June (top right panel), September (bottom left panel), and December (bottom right panel). It is interesting to note that the deviations indicate strong seasonal variations. Figure 7 illustrates that the model clearly overestimates the $h_{\mathrm{m}} F_{2}$ values during the daylight hours. Notice that duration of overestimation is longer during September month. The amplitude of the deviation is largest in the month of March. The magnitude of percent relative deviations of $\Delta h_{\mathrm{m}} F_{2}$ are found to be in the range of about -13 to $20 \%,-28$ to $13 \%$, -14 to $16 \%$, and -13 to $14 \%$, respectively for March, June, September, and December. June solstice season shows the largest deviations. The overall absolute deviation varies between $0-20 \%$, in broad agreement with those found in many earlier studies (e.g., Chuo and Lee, 2008; Yadav et al., 2010).

Figure 8 displays the diurnal variation of the relative deviations between model and data for $F_{2}$ peak electron density during high solar activity conditions. The plot in the upper left, upper right, bottom left, and bottom right panel indicates March, June, September, and December deviations, respectively. A close inspection of Fig. 8, one notes that deviations of $N_{\mathrm{m}} F_{2}$ have somewhat comparable values but their dependence on hour and month is different, apart from June solstice period, which demonstrates considerable fluctuations. The global model significantly overpredicted the observed value mostly during the nightside hours but underpredicted the observations during the daytime. Quantitatively, magnitude of $\Delta N_{\mathrm{m}} F_{2}$ varies from approximately -21 to $25 \%$ (March), -19 to $129 \%$ (June), -21 to $42 \%$ (September), and -22 to $24 \%$ (December). The average 
Ibadan

hmF2 Percent Relative Differences from CCIR IRI-2007 Model
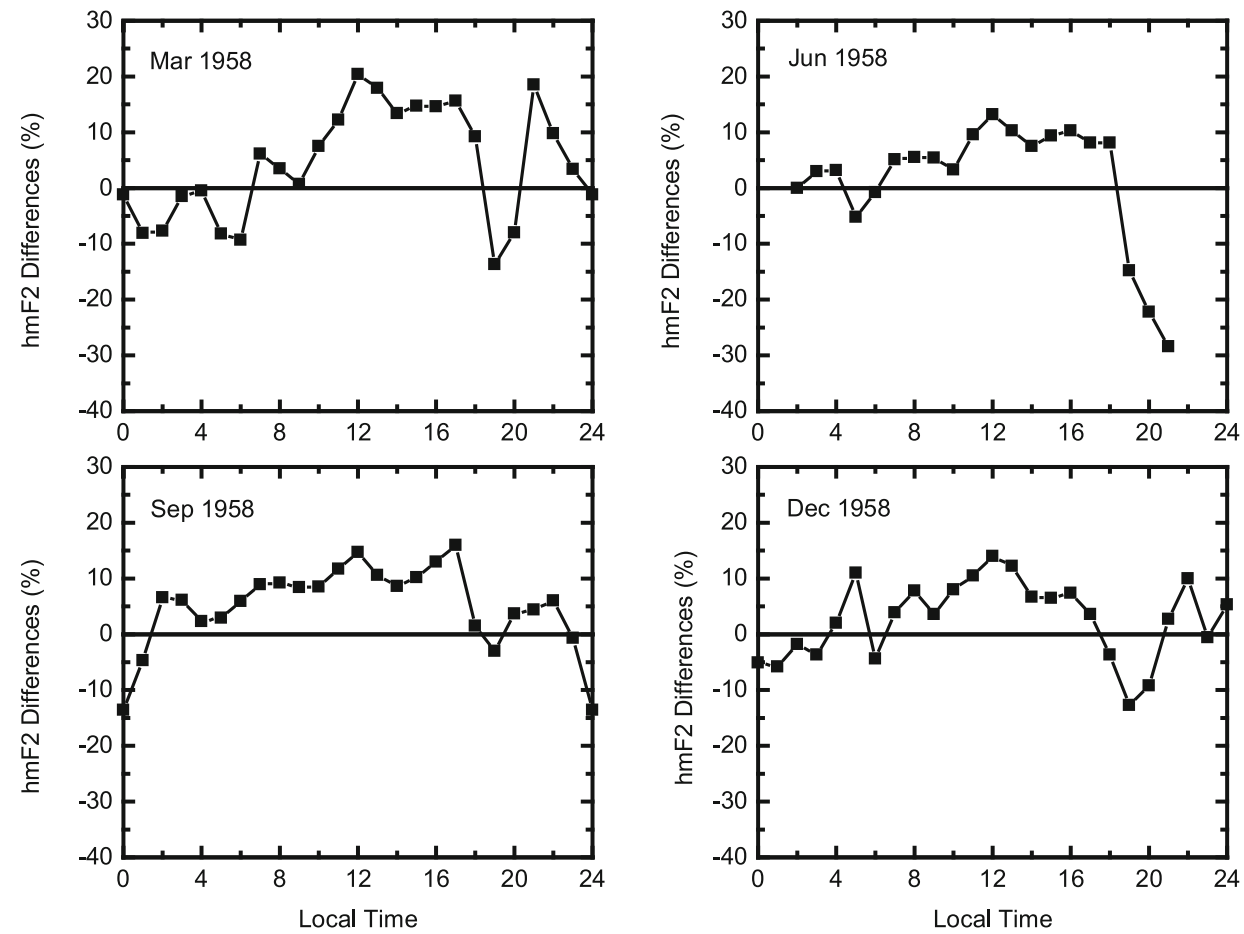

Fig. 7. Percent relative deviations between modeled and measured values of $h_{\mathrm{m}} F_{2}$ at Ibadan for March (upper left plot), June (upper right plot), September (lower left plot), and December (lower right plot) during quiet time and high solar flux conditions.

Ibadan

NmF2 Percent Relative Differences from IRI-2007 Model
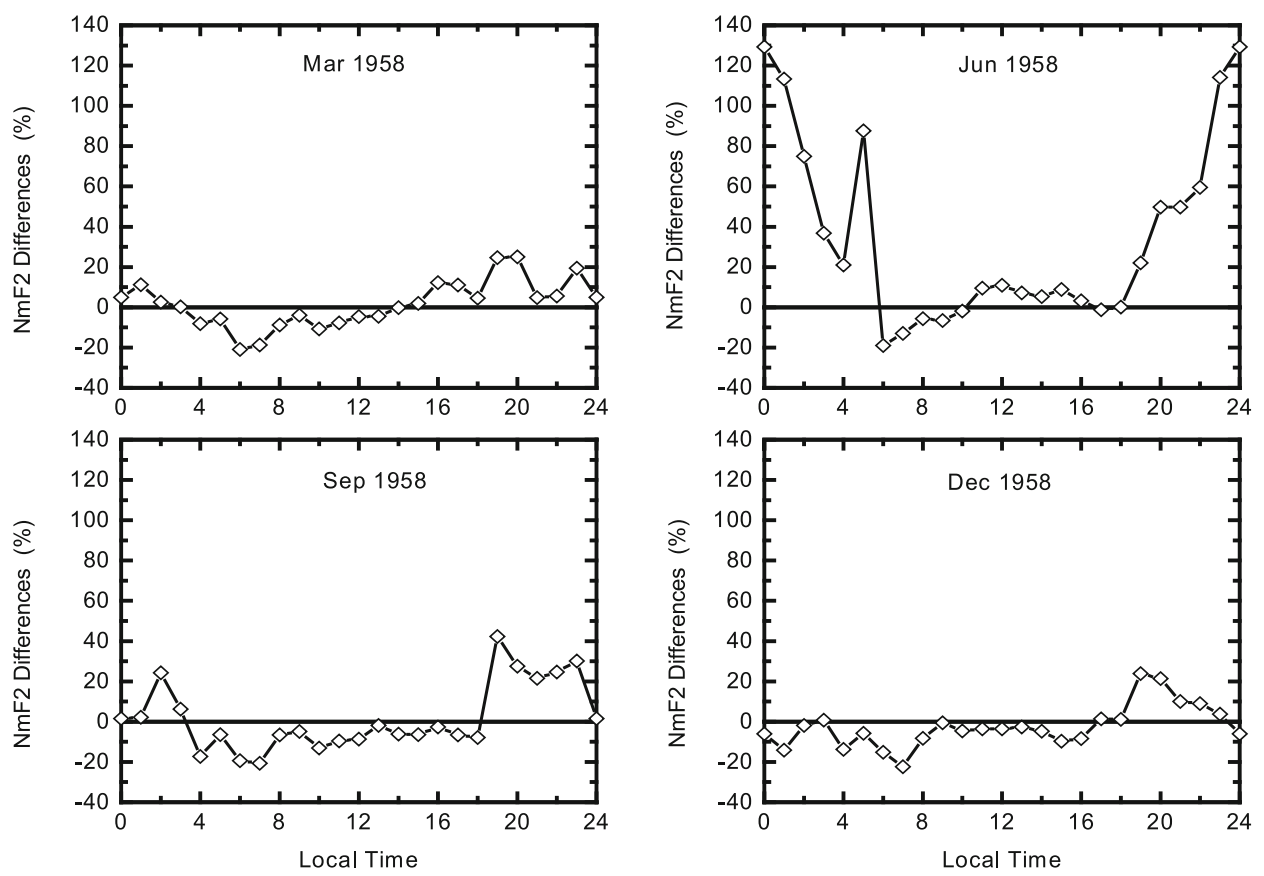

Fig. 8. Same as Fig. 7 except for $F_{2}$ layer maximum electron concentration.

absolute percent differences vary between $0-30 \%$.

Figure 9 shows local time variation of the percent relative deviations, $\Delta M_{3000} F_{2}$ between model results and data. The plot in the top left, top right, bottom left and bottom right panel indicates March, June, September and Decem- ber deviations, respectively. Figure 9 indicates that there are substantial hour-to-hour and month-to-month variations of deviation curves compared to variation observed in $h_{\mathrm{m}} F_{2}$ and $N_{\mathrm{m}} F_{2}$, although the magnitudes of the deviations from the observations are smaller. The largest amplitude of devi- 
Ibadan

\section{M3000F2 Percent Relative Differences from CCIR IRI-2007 Model}
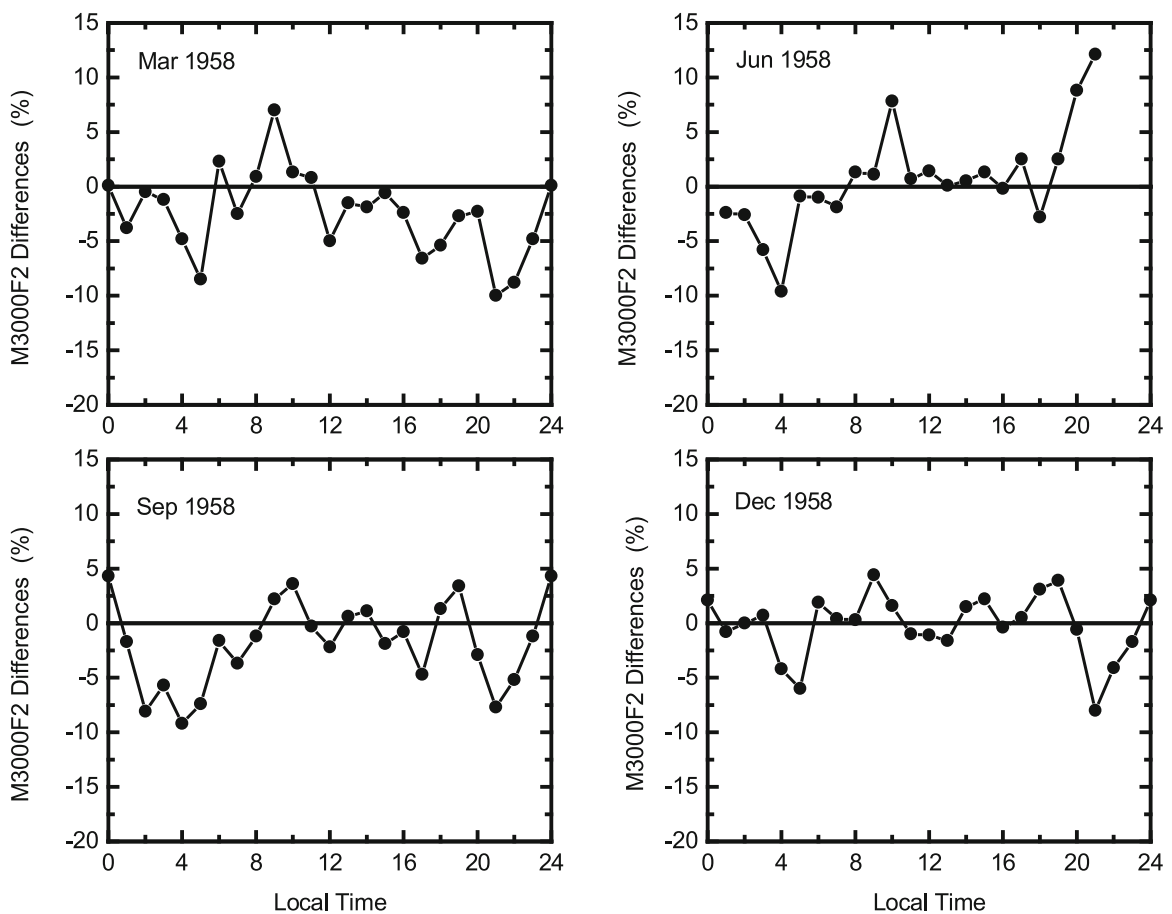

Fig. 9. Same as Fig. 7 except for propagation factor $M_{3000} F_{2}$.

ation occurs in June with a value greater than $10 \%$. The amplitude of the deviation curve varies from about -10 to $7 \%$ (March), -10 to $12 \%$ (June), -9 to $4 \%$ (September), and -8 to $4 \%$ (December), implying that IRI model seems to be largely underpredicts $M_{3000} F_{2}$ more than overpredicting propagation factor. On average, absolute percent disparity varies between about $0-10 \%$.

3.4 Quantitative assessment of the data and the model

The overall model error is estimated using normalized root-mean-square error for maximum height, maximum electron concentration, and propagation factor following the example of Pawlowski et al. (2008):

$$
E=\frac{\sqrt{\left\langle\left(F_{\text {model }}-F_{\text {data }}\right)^{2}\right\rangle}}{\sqrt{\left\langle F_{\text {data }}^{2}\right\rangle}},
$$

where $E$ is normalized RMS error, the \langle\rangle symbolizes taking a mean, and $F$ observational data. At $E=0$ the model and data agree perfectly, while at $E=1$, the model could be replaced by a zero line. With the value of $E>1$, the model results are diverging from the data, and most likely the model does not trend the data. Table 1 lists the results of normalized RMS errors for peak altitude and electron density of $F_{2}$ layer, and ionospheric propagation factor for the four seasonal periods. For $h_{\mathrm{m}} F_{2}$, December has the lowest normalized RMS error with a value of about $8 \%$, indicating that the model does a better job of capturing the trends and behaviour of $h_{\mathrm{m}} F_{2}$ during this period. The largest NRMS error is found in June with a value of about $14.8 \%$, while equinoxes lying between the two extremes. The model performs worst in June. Results of normalized RMS errors for maximum electron concentration are similar to those
Table 1. Percent normalized RMS errors for peak height, $F_{2}$ peak density, and propagation factor ${ }^{\mathrm{a}}$.

\begin{tabular}{lcccc}
\hline Parameter & March & June & September & December \\
\hline$h_{\mathrm{m}} F_{2}$ & 0.120 & 0.148 & 0.089 & 0.080 \\
$N_{\mathrm{m}} F_{2}$ & 0.095 & 0.173 & 0.123 & 0.087 \\
$M_{3000} F_{2}$ & 0.047 & 0.045 & 0.049 & 0.0305 \\
\hline
\end{tabular}

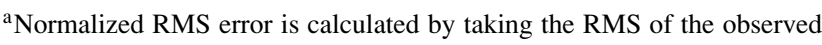
results of each parameter subtracted from the model results and then dividing by the RMS of the observed values of each parameter.

Table 2. Correlation coefficients values for IRI model predictions and measurements of ionospheric $F_{2}$ region parameters during high solar activity year.

\begin{tabular}{lcccc}
\hline Parameter & March & June & September & December \\
\hline$h_{\mathrm{m}} F_{2}$ & 0.89 & 0.82 & 0.95 & 0.92 \\
$N_{\mathrm{m}} F_{2}$ & 0.96 & 0.97 & 0.96 & 0.97 \\
$M_{3000} F_{2}$ & 0.97 & 0.98 & 0.98 & 0.98 \\
\hline
\end{tabular}

of peak height of electron density in that smallest and the largest values are found in solstices, with December solstice having the lowest value, $\sim 8.7 \%$, and June solstice with the largest value of, $\sim 17.3 \%$. Equinoxes NRMS errors are moderate. Thus the model performs better again in December solstice and worst during June solstice period. The results of normalized RMS errors for $M_{3000} F_{2}$ are highly encouraging. It is quite apparent that the model performs best in the month of December, while the model reproduces the trends and behaviour in the other months in roughly equal amount.

Table 2 gives the results of correlation coefficients be- 
tween the model and the data for all parameters at all seasons for high solar flux conditions. We can see that for a high solar activity year, the model and the data are excellently correlated for the all the parameters, except for $h_{\mathrm{m}} F_{2}$ during the months of March and June that show correlation of less than $90 \%$. The range of the correlations is relatively stable at $0.96-0.97$ and $0.97-0.98$ for $N_{\mathrm{m}} F_{2}$ and $M_{3000} F_{2}$, respectively, while the cross correlation of modeled and measured $h_{\mathrm{m}} F_{2}$ demonstrate a broad range of correlations, $0.82-0.95$.

\section{Discussion and Summary}

We have used ionosonde $h_{\mathrm{m}} F_{2}, N_{\mathrm{m}} F_{2}$, and $M_{3000} F_{2}$ data to characterize the structure and average behaviour of the equatorial $F_{2}$ region over the West African sector for quiet geomagnetic activity in a period of high solar activity. Our observations are fully consistent with the hourly and seasonal variation patterns of $h_{\mathrm{m}} F_{2}$ and $N_{\mathrm{m}} F_{2}$ reported by Lee and Reinisch (2006) for Jicamarca (Peru: $11.95^{\circ} \mathrm{S}$, $\left.76.87^{\circ} \mathrm{W}\right)$. Comparisons with the IRI model predictions demonstrate that the model predominantly overpredicts the $F_{2}$ peak altitude observations during the daytime, but there is visual tremendous agreement after midnight and 1000 local time for all seasons. The postsunset sharp "spike" in $h_{\mathrm{m}} F_{2}$ is not well formed in the modeled $h_{\mathrm{m}} F_{2}$ for all seasons. The model underpredicts data up to about $30 \%$ in June. In contrast to $h_{\mathrm{m}} F_{2}$, the model results remarkably portrayed the trends in the maximum electron concentration for all seasons. Although the percent relative deviations between IRI predictions and $N_{\mathrm{m}} F_{2}$ indicate that the empirical model underpredicts experimental $N_{\mathrm{m}} F_{2}$ values during the daytime and overpredicts $N_{\mathrm{m}} F_{2}$ during the nighttime for all seasons except for the month of June where the model underestimates the data for few hours between sunrise and 1000 local time, and significantly overestimate the observations at other times, reaching a value of about $130 \%$ at local midnight. Just like $F_{2}$ layer peak electron density, the modeled propagation factors closely follow the behaviour of the $M_{3000} F_{2}$ for all seasons. However, the predawn enhancement in $M_{3000} F_{2}$ is again not well formed compared to that of observation. Quantitatively, on average, the absolute range of value of relative deviation indicates that discrepancies between IRI predictions and the observational data are smallest in $M_{3000} F_{2}$, intermediate in $h_{\mathrm{m}} F_{2}$, and largest in $N_{\mathrm{m}} F_{2}$. It is worth mentioning also that the model performs relatively better in the month of December than the rest of the month for all parameters. By and large, our data concur with those of Adeniyi et al. (2003) and Obrou et al. (2003) who carried out the same exercise for same West African sector but for Ouagadougou (Burkina Faso: $12.4^{\circ} \mathrm{N}, 1.5^{\circ} \mathrm{W}$ ) and Korhogo (Cote-d'voire: $3.9^{\circ} \mathrm{N}, 5.4^{\circ} \mathrm{W}$ ) during low and high solar activity.

The deviations, which are observed in this research, are largely ascribed to the low order spherical harmonics used to develop the CCIR model. It is important to say that even though, IRI-2007 is an empirical model based on mixed data (ionosonde, incoherent scatter, rocket, and satellite measurements), the ground-based ionosonde measurements were mostly from the ionospheric stations located in the midlatitudes regions, in this case, IRI does an excellent job of replicating morphology of equatorial ionospheric $F_{2}$ layer essential characteristic over the West African longitude sector; a region which is not represented in the data base used in the IRI model formulation.

Acknowledgments. The authors wish to acknowledge Department of Physics, University of Ibadan, Nigeria for providing observational data used in this work. The authors are so grateful to the referee for the wonderful job he has done on the original draft of the paper. The constructive comments and suggestions have led to reprocessing many of our important plots and reanalysing them in the comparisons section. Of a truth, the suggested website and sample data prompted us to complete this work. One of the authors, O. S. Oyekola, specially thanks Dr. Dieter Bilitza (guest editor) for enlightening discussion and guidance during the revision phase of this paper. We gratefully acknowledge United State National Oceanic and Atmospheric Administration (NOAA) for providing $h_{\mathrm{m}} F_{2}, f_{\mathrm{o}} F_{2}$, and $M_{3000} F_{2}$ data from the IRI-2007 website at: http://omniweb.gsfc.nasa.gov/vitmo/iri_vitmo.html.

\section{References}

Abdu, M. A., I. S. Batista, B. W. Reinisch, and A. J. Carrasco, Equatorial $\mathrm{F}$ layer heights, evening prereversal electric field, and night $\mathrm{E}$ layer density in the American sector: IRI validation with observation, $A d v$. Space Res., 34, 1953-1965, 2004.

Adeniyi, J. O., D. Bilitza, S. M. Radicella, and A. A. Willoughby, Equatorial F2 peak parameters in the IRI model, Adv. Space Res., 31(3), 507512, 2003.

Anderson, D., A. Anghel, K. Yumoto, M. Ishittuka, and E. Kudeki, Estimating daytime vertical $\mathbf{E} \times \mathbf{B}$ drift velocities in the equatorial $\mathrm{F}$ region using ground-based magnetometer observations, Geophys. Res. Lett., 29, doi:10.1029/2001GL014562, 2002.

Appleton, E. V., Two anomalies in the ionosphere, Nature, 157, 691, 1946. Bertoni, F., Y. Sahai, W. L. C. Lima, P. R. Fagundes, V. G. Pillat, F. BeckerGuedes, and J. R. Abalde, IRI-2001 model predictions compared with ionospheric data observed at Brazilian low latitude stations, Ann. Geophys., 24, 2191-2200, 2006.

Bilitza, D., International Reference Ionosphere 2000, Radio Sci., 36, 261275, 2001.

Bilitza, D., N. M. Sheikh, and R. Eyfrig, A global model for the height of the F2-peak using M3000 values from the CCIR numerical map, Telecom. J., 46, 549-553, 1979.

Bilitza, D., C. Koblinsky, B. Beckley, S. Zia, and R. Williamson, Using IRI for the comparison of ionospheric corrections for altimeter data analysis, Adv. Space Res., 15(2), 113-120, 1995.

Bittencourt, J. A. and M. Chryssafidis, On the IRI-model predictions for the low-latitude ionosphere, J. Atmos. Terr. Phys., 56, 995-1009, 1994.

Bradley, P., Use of electron density profiles in HF propagation assessment, Adv. Space Res., 11(10), 117-134, 1991.

Chuo, Y. J. and C. C. Lee, Ionospheric variability at Taiwan low latitude station: Comparison between observations and IRI-2001 model, $A d v$. Space Res., 42, 673-681, 2008.

Huang, C., C. Liu, H. Yeh, W. Tsai, C. Wang, K. Yeh, K. Lin, and H. Tsai, IRI model application in low latitude ionospheric tomography, Adv. Space Res., 18(2), 237-240, 1996.

Kelso, J. M., A procedure for the determination of the vertical distribution of the electron density in the ionosphere, J. Geophys. Res., 57, 357-367, 1952

Lee, C.-C. and B. W. Reinisch, Quiet-condition hmF2, NmF2, and Bo variations at Jicamarca and comparison with IRI-2001 during solar maximum, J. Atmos. Sol.-Terr. Phys., 68, 2138-2146, 2006.

Namba, S. and K.-L. Maeda, Radio Wave Propagation, 86 pp., Corona, Tokyo, 1939.

Obrou, O. K., D. Bilitza, J. O. Adeniyi, and S. M. Radicella, Equatorial F2layer peak height and correlation with vertical ion drift and $\mathrm{M}(3000) \mathrm{F} 2$, Adv. Space Res., 31(3), 513-520, 2003.

Oyekola, O. S., Variation in the ionospheric propagation factor M(3000)F2 at Ouagadougou, Burkina Faso, Adv. Space Res., 46, 7480, doi:10.1006/j.asr.2010.02.017, 2010.

Oyekola, O. S., Comparisons of foF 2 with IRI model and equatorial vertical drifts, Adv. Space Res., 48(8), 1318-1326, doi:10. 1016/j.asr.2011.06.027, 2011.

Pawlowski, D. J., A. J. Ridley, I. Kim, and D. S. Bernstein, Global model 
comparison with Millstone Hill during September 2005, J. Geophys. Res., 113, A01312, doi:1029/2007JA012390, 2008.

Reinisch, B. W. and X. Huang, Low latitude digisonde measurements and comparison with IRI, Adv. Space Res., 18, 5-12, 1996.

Rios, V. H., C. F. Medina, and P. Alvarez, Comparison between IRI predictions and digisonde measurements at Tucuman, J. Atmos. Sol.-Terr. Phys., 69, 569-577, 2007.

Sethi, N. K., R. S. Dabas, and K. Sharma, Comparison between IRI predictions and digital ionosonde measurements of hmF2 at New Delhi during low and moderate solar activity, J. Atmos. Sol.-Terr. Phys., 70, 756-763, 2008.

Yadav, S., R. S. Dabas, R. M. Das, A. K. Upadhayaya, K. Sharma, and A. K. Gwal, Diurnal and seasonal variation of F2-layer ionospheric parameters at equatorial ionization anomaly crest region and their comparison with IRI-2001, Adv. Space Res., 45, 361-367, 2010.

O. S. Oyekola (e-mail: oyedemio@yahoo.com) and P. R. Fagundes 